\title{
Lymph Node Status in Colorectal Cancer; Is There a Case for Auditing the Pathologist and the Surgeon?
}

\author{
Emil Salmo ${ }^{1, *}$ and Najib Haboubi ${ }^{1}$ \\ ${ }^{1}$ Department of Histopathology, Pennine Acute Hospitals NHS Trust, Royal Oldham Hospital, Oldham, United Kingdom \\ "Corresponding author: Consultant Pathologist, Department of Histopathology, Pennine Acute Hospitals NHS Trust, Royal Oldham Hospital, Rochdale Road, OL12JH, Oldham, \\ United Kingdom. Email: emilsalmo@hotmail.com
}

Received 2018 September 05; Accepted 2018 December 19.

\begin{abstract}
The significance of nodal metastasis as a prognostic factor in colorectal cancer is universally recognised and accepted. This article discusses the various factors that govern lymph node harvest and how to improve that. We will discuss the outcome of lymph node harvest as a possible form of auditing the surgical technique and the pathologist dedication.
\end{abstract}

Keywords: Lymph Node, Colorectal Cancer, Pathologist

\section{Context}

Lymph node status plays a central part in all staging systems including the most widely used Dukes' staging and the TNM (1-3).

The aim of successful oncological surgery is the complete removal of the tumour and the lymph node draining basin whilst an essential aspect of a good histopathological report is to inform on the various prognostic parameters which include the lymph node status. There is important association between higher nodal yield and survival, particularly for node negative disease $(4,5)$. However, in node positive colorectal cancer the concept of lymph node ratio may be a better prognostic parameter although the impact of this concept is still not universally implemented. Guidelines usually recommend a minimum of 12 lymph nodes to be recovered from a resection specimen as standard, yet such evidence is questionable. The use of neoadjuvant chemoradiotherapy in the treatment of mainly colorectal cancer including down-staging in rectal cancer paradoxically suggests that the presence of smaller of lymph nodes or occasionally complete absence of nodes are associated with improved survival (6) hence using a strict number of lymph nodes as a quality measure is probably not always appropriate.

Nodal metastasis is a well-known prognostic indicator for long term outcome and prognosis because it influences patients' selection for further treatment such as chemoradiotherapy (7-12).

\section{Factors That Govern Lymph Node Yield}

It has been observed that there is large amount of variation in nodal yield amongst colorectal surgeons and some of these factors rely on the surgeon or the pathologist.

\section{Tumour Factors}

Studies have demonstrated that poorly differentiated carcinomas and tumour with advanced T-stage result in higher nodal yield, probably due to the fact that poorly differentiated tumours stimulate stronger immune response within the body (13-15). This would be probably explained by the possibility that a potent immune response which could be elicited by the adverse prognostic factors rather than to an actual increase in the number of lymph nodes retrieved from the specimen.

\section{Anatomical Location}

Many studies have demonstrated that, in colorectal cancer, the number of lymph nodes decreases from proximal to distal location (13-18) and been significantly a smaller number of lymph nodes in the sigmoid colon and the rectum which contain fewer and smaller lymph nodes. Some studies have shown that more lymph nodes could be retrieved along the distribution of the superior mesenteric artery compared to the inferior mesenteric vessels (19-21). 


\section{Age}

Studies have shown that there is an inverse relationship between patient's age and the lymph node yield from the resection specimens of colorectal cancer. Shen et al. (14) shown in a study of 434 consecutive colorectal cancer specimens that the mean number of nodal yield was higher in patients age $\leq 60$ vs. $>60$. The likely one explanation is that older patients have a weaker immune response compared to young individuals (22). In addition, involution of lymphoid tissue with advancing age is an additional factor together with the tendency of the surgeons to perform less radical resection in older individuals to decrease the risk of post-operative complications. Luperto et al. (23) showed that lymph node yield from colorectal cancer specimens is affected by factors such as age, sex, BMI and tumour size together with the use of neoadjuvant chemoradiotherapy.

\section{Surgeon and the Workload}

Good evidence in the literature is present suggesting that the nodal yield in colorectal cancer is a quality measure of the care provided by the clinicians and pathologist (20, 24-27). In a study from the United States between 1989 and 2005 with more than 1000 patients involved and 40 surgeons, Dillman et al. (20) showed that fellowship training and case volume are correlated strongly with the number of lymph nodes retrieved from the resection specimens. In this study 77\% of fellowship trained doctors had more than 12 lymph nodes retrieved vs. 63\% of the nonfellowship trained doctors. A study by Shaw et al. (28) also showed that colorectal surgeons are better in getting more lymph nodes than the general surgeons.

\section{Pathologist}

The pathologist role in lymph node retrieval has always been of utmost importance. Rieger et al. (29) compared the number of lymph nodes from resections performed by a single high volume surgeon at two different hospitals with 2 separate pathology departments. In this study, the median lymph node yield was 10 and 19 for the 2 separate departments respectively. One study showed that biomedical scientists identified more lymph nodes within specimens than consultant pathologists as they dedicated more time to the task (28). A more recent study (30) showed that the dedication of the pathologist has a critical role on the number of lymph nodes detected but had no effect on survival raising the argument on why spend extra time and effort to dissect more lymph nodes. However, the number of patients in this study was small and the follow up period was short.

\section{Strategies to Improve Lymph Node Yield}

Techniques to increase the number of lymph nodes from colorectal resection specimens have been established for many years (31-33). Gilchrist and David a surgeon from Chicago (34), in 1938 introduced fat clearing technique that required using chemicals that included substances that have been proven later to be toxic. This fact with the excess time needed to process the specimens and the additional costs have been the main reasons for the lack of its wider implementations. In our hands however we used special vacuum extractor and took no longer than 2 extra days (35). An undeniable fact is that the use of these methods can greatly increase the number of lymph nodes from colorectal resection specimens (31-33). Wang et al. (36) on the other hand had a simple approach by immersing of the fat in pure alcohol for up to 48 hours and this lead to a significant increase in the number of retrieved lymph nodes from the colorectal resection specimens and ultimately more patient upstaged. This technique is simple, safe and cheap. The application of these techniques is important in rectal cancer specimens for neoadjuvant chemotherapy as this treatment has been shown to greatly reduce the number of retrieved lymph nodes from these sorts of specimens. Wang et al. stated that the use of lymph node clearance method enhanced the mean number of lymph nodes from 5.2 to 17.3 and led to a significant increase in the number of lymph nodes which contained metastatic carcinoma (36). This finding is important especially in advanced staged disease as the patient can be offered further treatment such as adjuvant therapy. One study demonstrated that up to 83\% of the lymph nodes recovered following fat clearance methods ranged in size from $1-5 \mathrm{~mm}$ and up to $4.4 \%$ of these lymph nodes contained metastatic tumour (37). Dias et al. (38) also showed that Carnoy's solution resulted in more lymph nodes and fewer specimen containing less than 12 lymph nodes. Tattooing also shown by Okada et al. to increase the number of retrieved lymph nodes by up to $51 \%$ by making these lymph nodes more visible during the dissection stage (39).

\section{How Many Lymph Nodes Needed for Accurate Stag- ing and Are Twelve Lymph Nodes Enough?}

The recommended minimum number of lymph nodes yield of 12 was highlighted in the 1990 working party report to the world congress of gastroenterology in Sydney (40) and this was based on data published in 1989 from nonrandomised observational one-centre study involving 103 colorectal cancer specimens by Scott and Grace (33). Scott and Grace found that when at least 13 lymph nodes are examined histologically, more than $90 \%$ of the specimen con- 
taining nodal metastases. Nelson et al. (41) in 2001 also showed that examining 12 lymph nodes would identify lymph node positivity in more than $90 \%$ of times. Further studies also recommended using minimum lymph node count that ranged from 7 - 40 (42-44). This wide variation may be related to dissimilar statistical endpoints such as detection of metastatic nodules vs patient's outcomes and more relevant, to the median or mean number of lymph nodes examined.

\section{Does the Lymph Node Ratio Relate to Prognosis?}

It has been highlighted in the literature that due to the variability of the number of lymph nodes between individuals it is more appropriate to show the percentage of positive nodes rather than the absolute number. The lymph node ratio is defined as the ratio of positive lymph nodes and the total number of lymph nodes retrieved from the specimen. This was first highlighted by Berger et al. (45). However, the question remains regarding the exact number required in order to predict outcome but evidence suggest that a higher lymph node ratio equates to worse prognosis. Vather et al. (44) showed that the 5 year mortality of $40 \%-45 \%$ relates to lymph node ratio value of $0-0.10$ and this increased to $80-90 \%$ with lymph node ratio value of 0.91 - 1.0. Wang et al. (46) showed that the 5 year overall survival is $64.8 \%$ with a lymph node ratio of less than $0.07,56.2 \%$ with a lymph node ratio ranging between 0.07 - $0.25,45.1 \%$ with a lymph node ratio of more than 0.25 0.50 and decreasing to $29.6 \%$ when the lymph node ratio is more than 0.50 . However, whilst recent studies support the evidence of lymph node ratio, an attempt to retrieve as many lymph nodes as possible when examining colorectal cancer specimens remains the gold standard as by definition the lymph node ratio still depends on the number of lymph nodes retrieved from these specimens.

\section{Should Lymph Node Yield be Used as a Measure of Quality Control?}

Lymph node yield has been adopted by many as a quality measure in colorectal cancer as the data is simple and associated with prognosis, however, as stated earlier it is important to highlight that the number of lymph nodes resected from colorectal cancer specimens depends highly on a variety of parameters that are independent of the quality of care. So it is neither fair nor scientific to always put the blame on the surgeon or the pathologist if the number is less than 12 but advise if such figure cannot be achieved on regular basis then a discussion between the pathologist and the surgeon should take place to discuss the issue and hence satisfy the audit process.

\section{Conclusions}

1. Lymph node yield is essential for accurately staging colorectal cancer specimens.

2. Fat clearance methods enhance the number of lymph nodes retrieved from these specimens and the pathologist remains an important factor in the retrieval of as many lymph nodes as possible and this should be used as an auditing tool.

3. Using various figures are optimal number needs to be re-evaluated. As stated earlier there are numerous factors which influence lymph node yield and the quality of the surgery is only one of them. Taking that into consideration we feel that lymph node yield should be used as but not the sole indicator of good surgery. Therefore, it could be used as an auditing tool by the pathologist.

\section{Acknowledgments}

We would like to thank Nicole Lynch for her help in writing the manuscript.

\section{Footnotes}

Authors' Contribution: Both authors contributed equally to the manuscript.

Conflict of Interests: Authors mention that there is no conflict of interests in this study.

Funding/Support: No funding to declare.

\section{References}

1. Compton CC, Fielding LP, Burgart LJ, Conley B, Cooper HS, Hamilton SR, et al. Prognostic factors in colorectal cancer. College of American Pathologists Consensus Statement 1999. Arch Pathol Lab Med. 2000;124(7):979-94. doi: 10.1043/00039985(2000)124<0979:PFICC>2.0.CO;2. [PubMed: 10888773].

2. Dukes CE. The classification of cancer of the rectum.J Pathol Bacteriol. 1932;35(3):323-32. doi: 10.1002/path.1700350303.

3. Sobin LH. Sobin LH, Wittekind C, editors. TNM classification of malignant tumours. 6th ed. New York: Wiley-Liss; 2002.

4. Budde CN, Tsikitis VL, Deveney KE, Diggs BS, Lu KC, Herzig DO. Increasing the number of lymph nodes examined after colectomy does not improve colon cancer staging. J Am Coll Surg. 2014;218(5):1004-11. doi: 10.1016/j.jamcollsurg.2014.01.039. [PubMed: 24661856].

5. Chang GJ, Rodriguez-Bigas MA, Skibber JM, Moyer VA. Lymph node evaluation and survival after curative resection of colon cancer: Systematic review. J Natl Cancer Inst. 2007;99(6):433-41. doi: 10.1093/jnci/djk092. [PubMed: 17374833].

6. Habr-Gama A, Perez RO, Proscurshim I, Rawet V, Pereira DD, Sousa AH, et al. Absence of lymph nodes in the resected specimen after radical surgery for distal rectal cancer and neoadjuvant chemoradiation therapy: What does it mean? Dis Colon Rectum. 2008;51(3):277-83. doi: 10.1007/s10350-007-9148-5. [PubMed: 18183463]. 
7. Baxter NN, Virnig DJ, Rothenberger DA, Morris AM, Jessurun J, Virnig BA. Lymph node evaluation in colorectal cancer patients: A population-based study. J Natl Cancer Inst. 2005;97(3):219-25. doi: 10.1093/jnci/dji020. [PubMed: 15687365].

8. Quasar Collaborative G, Gray R, Barnwell J, McConkey C, Hills RK, Williams NS, et al. Adjuvant chemotherapy versus observation in patients with colorectal cancer: A randomised study. Lancet. 2007;370(9604):2020-9. doi: 10.1016/S0140-6736(07)61866-2. [PubMed: 18083404].

9. [No authors listed]. Comparison of fluorouracil with additional levamisole, higher-dose folinic acid, or both, as adjuvant chemotherapy for colorectal cancer: A randomised trial. QUASAR Collaborative Group. Lancet. 2000;355(9215):1588-96. [PubMed: 10821362].

10. McDonald JR, Renehan AG, O'Dwyer ST, Haboubi NY. Lymph node harvest in colon and rectal cancer: Current considerations. World J Gastrointest Surg. 2012;4(1):9-19. doi: 10.4240/wjgs.v4.i1.9. [PubMed: 22347537]. [PubMed Central: PMC3277879].

11. O'Dwyer ST, Haboubi NY, Johnson JS, Gardy R. Detection of lymph node metastases in colorectal carcinoma. Colorectal Dis. 2001;3(5):288-94. [PubMed: 12790948].

12. Schofield JB, Mounter NA, Mallett R, Haboubi NY. The importance of accurate pathological assessment of lymph node involvement in colorectal cancer. Colorectal Dis. 2006;8(6):460-70. doi: 10.1111/j.14631318.2006.01044.x. [PubMed: 16784464]

13. Okuyama $\mathrm{T}$, Oya $\mathrm{M}$, Ishikawa $\mathrm{H}$. Budding as a risk factor for lymph node metastasis in pT1 or PT2 well-differentiated colorectal adenocarcinoma. Dis Colon Rectum. 2002;45(5):628-34. [PubMed: 12004212].

14. Shen SS, Haupt BX, Ro JY, Zhu J, Bailey HR, Schwartz MR. Number of lymph nodes examined and associated clinicopathologic factors in colorectal carcinoma. Arch Pathol Lab Med. 2009;133(5):781-6. doi: 10.1043/1543-2165-133.5.781. [PubMed:19415953].

15. Tekkis PP, Smith JJ, Heriot AG, Darzi AW, Thompson MR, Stamatakis JD, et al. A national study on lymph node retrieval in resectional surgery for colorectal cancer. Dis Colon Rectum. 2006;49(11):1673-83. doi:10.1007/s10350-006-0691-2. [PubMed: 17019656]

16. Caplin S, Cerottini JP, Bosman FT, Constanda MT, Givel JC. For patients with Dukes' B (TNM Stage II) colorectal carcinoma, examination of six or fewer lymph nodes is related to poor prognosis. Cancer. 1998;83(4):666-72. [PubMed: 9708929].

17. Chen SL, Bilchik AJ. More extensive nodal dissection improves survival for stages I to III of colon cancer: A population-based study. Ann Surg. 2006;244(4):602-10. doi:10.1097/01.sla.0000237655.11717.50. [PubMed: 16998369]. [PubMed Central: PMC1856560].

18. Cianchi F, Palomba A, Boddi V, Messerini L, Pucciani F, Perigli G, et al. Lymph node recovery from colorectal tumor specimens: recommendation for a minimum number of lymph nodes to be examined. World J Surg. 2002;26(3):384-9. doi: 10.1007/s00268-001-0236-8. [PubMed: 11865379].

19. Canessa CE, Badia F, Fierro S, Fiol V, Hayek G. Anatomic study of the lymph nodes of the mesorectum. Dis Colon Rectum. 2001;44(9):1333-6. [PubMed: 11584211].

20. Dillman RO, Aaron K, Heinemann FS, McClure SE. Identification of 12 or more lymph nodes in resected colon cancer specimens as an indicator of quality performance. Cancer. 2009;115(9):1840-8. doi: 10.1002/cncr.24185. [PubMed: 19208427].

21. Topor B, Acland R, Kolodko V, Galandiuk S. Mesorectal lymph nodes: Their location and distribution within the mesorectum. Dis Colon Rectum. 2003;46(6):779-85. doi: 10.1097/01.DCR.0000069955.51592.56. [PubMed: 12794580].

22. Galon J, Costes A, Sanchez-Cabo F, Kirilovsky A, Mlecnik B, LagorcePages C, et al. Type, density, and location of immune cells within human colorectal tumors predict clinical outcome. Science. 2006;313(5795):1960-4. doi: 10.1126/science.1129139. [PubMed: 17008531].

23. Luperto M, Gasparini G, Orsenigo E, Carlucci M. Factors influencing lymph node yield in colorectal cancer. EurJ Surg Oncol.2018;44(4):544. doi:10.1016/j.ejso.2018.01.036.

24. Bui L, Rempel E, Reeson D, Simunovic M. Lymph node counts, rates of positive lymph nodes, and patient survival for colon cancer surgery in Ontario, Canada: A population-based study. J Surg Oncol. 2006;93(6):439-45. doi:10.1002/jso.20499. [PubMed:16615148].

25. Goldstein NS, Sanford W, Coffey M, Layfield LJ. Lymph node recovery from colorectal resection specimens removed for adenocarcinoma. Trends over time and a recommendation for a minimum number of lymph nodes to be recovered. Am J Clin Pathol. 1996;106(2):209-16. [PubMed: 8712176].

26. Pheby DF, Levine DF, Pitcher RW, Shepherd NA. Lymph node harvests directly influence the staging of colorectal cancer: Evidence from a regional audit. J Clin Pathol. 2004;57(1):43-7. [PubMed: 14693834]. [PubMed Central: PMC1770175]

27. Wong SL, Ji H, Hollenbeck BK, Morris AM, Baser O, Birkmeyer JD. Hospital lymph node examination rates and survival af ter resection for colon cancer. JAMA. 2007;298(18):2149-54. doi 10.1001/jama.298.18.2149. [PubMed: 18000198].

28. Shaw A, Collins EE, Fakis A, Patel P, Semeraro D, Lund JN. Colorectal surgeons and biomedical scientists improve lymph node harvest in colorectal cancer. Tech Coloproctol. 2008;12(4):295-8. doi 10.1007/s10151-008-0438-2. [PubMed: 19018472].

29. Rieger NA, Barnett FS, Moore JW, Ananda SS, Croxford M, Johns J, et al. Quality of pathology reporting impacts on lymph node yield in colon cancer. J Clin Oncol. 2007;25(4):463. author reply 463-4. doi 10.1200/JCO.2006.09.2304. [PubMed: 17264350].

30. Unger LW, Muckenhuber M, Riss S, Argeny S, Stift J, Mesteri I, et al. Effect of pathologist's dedication on lymph node detection rate and postoperative survival in colorectal cancer. Colorectal Dis 2018;20(7):O173-80. doi: 10.1111/codi.14241. [PubMed: 29706021].

31. Jass JR, Miller K, Northover JM. Fat clearance method versus manual dissection of lymph nodes in specimens of rectal cancer. Int J Colorectal Dis. 1986;1(3):155-6. [PubMed: 3611943]

32. Pickren JW. Current concepts in cancer. Nodal clearance and detection. JAMA. 1975;231(9):969-71. [PubMed: 1173109].

33. Scott KW, Grace RH. Detection of lymph node metastases in colorectal carcinoma before and after fat clearance. Br J Surg. 1989;76(11):1165-7. [PubMed: 2688803].

34. Gilchrist RK, David VC. Lymphatic spread of carcinoma of the rectum. Ann Surg. 1938;108(4):621-42. [PubMed: 17857257]. [PubMed Central: PMC1387036].

35. Haboubi NY, Clark P, Kaftan SM, Schofield PF. The importance of combining xylene clearance and immunohistochemistry in the accurate staging of colorectal carcinoma. J R Soc Med. 1992;85(7):386-8. [PubMed: 1378498]. [PubMed Central: PMC1293543].

36. Wang H, Safar B, Wexner SD, Denoya P, Berho M. The clinical sig nificance of fat clearance lymph node harvest for invasive rectal adenocarcinoma following neoadjuvant therapy. Dis Colon Rectum. 2009;52(10):1767-73. doi: 10.1007/DCR.0b013e3181b14eaf. [PubMed: 19966611].

37. Hernanz F, Garcia-Somacarrera E, Fernandez F. The assessment of lymph nodes missed in mesenteric tissue after standard dissection of colorectal cancer specimens. Colorectal Dis. 2010;12(7 Online):e57-60. doi: 10.1111/j.1463-1318.2009.01987.x. [PubMed: 19575743].

38. Dias AR, Pereira MA, de Mello ES, Nahas SC, Cecconello I, Ribeiro UJ. Lymph node yield after neoadjuvant chemoradiotherapy in rectal cancer specimens: A randomized trial comparing two fixatives. Dis Colon Rectum. 2018;61(8):888-96. doi: 10.1097/DCR.0000000000001097. [PubMed: 29944580].

39. Okada K, Sadahiro S, Ogimi T, Miyakita H, Saito G, Tanaka A, et al. Tattooing improves the detection of small lymph nodes and increases the number of retrieved lymph nodes in patients with rectal cancer who receive preoperative chemoradiotherapy: A randomized controlled clinical trial. Am J Surg. 2018;215(4):563-9. doi 10.1016/j.amjsurg.2017.06.030. [PubMed: 28693841]. 
40. Fielding LP, Arsenault PA, Chapuis PH, Dent O, Gathright B, Hardcastle JD, et al. Clinicopathological staging for colorectal cancer: An international documentation system (IDS) and an international comprehensive anatomical terminology (ICAT). J Gastroenterol Hepatol. 1991;6(4):325-44. [PubMed: 1912440].

41. Nelson H, Petrelli N, Carlin A, Couture J, Fleshman J, Guillem J, et al Guidelines 2000 for colon and rectal cancer surgery. J Natl Cancer Inst. 2001;93(8):583-96. [PubMed: 11309435].

42. Le Voyer TE, Sigurdson ER, Hanlon AL, Mayer RJ, Macdonald JS, Catalano PJ, et al. Colon cancer survival is associated with increasing number of lymph nodes analyzed: A secondary survey of intergroup trial INT-0089. J Clin Oncol. 2003;21(15):2912-9. doi: 10.1200/JCO.2003.05.062. [PubMed: 12885809].

43. Tepper JE, O'Connell MJ, Niedzwiecki D, Hollis D, Compton C, Benson $\mathrm{AB} 3 \mathrm{rd}$, et al. Impact of number of nodes retrieved on out- come in patients with rectal cancer.J Clin Oncol. 2001;19(1):157-63. doi: 10.1200/JCO.2001.19.1.157. [PubMed: 11134208].

44. Vather R, Sammour T, Zargar-Shoshtari K, Metcalf P, Connolly A, Hill A. Lymph node examination as a predictor of long-term outcome in Dukes B colon cancer. Int J Colorectal Dis. 2009;24(3):283-8. doi: 10.1007/s00384-008-0540-y. [PubMed: 18716784].

45. Berger AC, Sigurdson ER, LeVoyer T, Hanlon A, Mayer RJ, Macdonald $\mathrm{JS}$, et al. Colon cancer survival is associated with decreasing ratio of metastatic to examined lymph nodes. J Clin Oncol. 2005;23(34):870612. doi: 10.1200/JCO.2005.02.8852. [PubMed:16314630].

46. Wang J, Kulaylat M, Rockette H, Hassett J, Rajput A, Dunn KB, et al. Should total number of lymph nodes be used as a quality of care measure for stage III colon cancer? Ann Surg. 2009;249(4):559-63. doi: 10.1097/SLA.ob013e318197f2c8. [PubMed: 19300237]. 